\title{
KIRSAL KALKINMA UYGULAMALARI ÜZERINNE BİR DEĞERLENDİRME: TKDK (TARIM VE KIRSAL KALKINMAYI DESTEKLEME KURUMU) ÖRNEĞİ
}

\section{Kadir BAHTIYYAR ${ }^{1}$}

\section{ÖZET}

Türkiye Tarım politikaları içinde Kırsal Kalkınma her geçen yıl önemini arttırmaktadır. Ekonomisi içerisinde tarımın önemli bir yer teşkil ettiği Türkiye özellikle Kırsala yapılacak destek ve yatırımlarla $\mathrm{AB}$ seviyelerinde güçlü bir kırsal kalkınma yakalamayı hedeflemektedir. Kırsal Kalkınma politikaları AB süreciyle yeni bir seyir kazanmıştır. AB, aday ülke statüsü kazanmış ülkelerin Tarım ve Kırsal Kalkınmalarının sağlanması ve topluluk standartlarına yükseltilmesini amaçlayan mali yardım ve hibeler sağlamaktadır.

Tarım ve Kırsal Kalkınmanın topluluk standartlarına ulaştırılmasına yönelik çalışmalar süreç içerisinde önem kazanmıştır. $A B$, üye ve aday ülkelerin Kırsal Kalkınmada topluluk standartlarına uyumlu hale gelmeleri için bu ülkelere fonlar tahsis ederek bu süreci hızlandırmaktadır. Tarım ve Kırsal Kalkınmayı Destekleme Kurumu (TKDK), AB katılım öncesi mali yardım aracı IPA (Instrument for Pre-accession Assistance) nın 5. Bileşeni olan Kırsal Kalkınma bileşeninin uygulayıcı kurumu olarak 2008 yılında kurulmuştur. Kurum, AB ve Türkiye'nin oluşturduğu fonlarla Kırsal Kalkınma yatırımlarına proje bazlı hibe şeklinde desteklerde bulunmaktadır. Çalışmada TKDK ve Türkiye'nin Kırsal Kalkınmasına yaptığı katkılar ortaya konmaya çalışılmıştır.

Anahtar Kelimeler: Avrupa Birliği, Kırsal kalkınma, IPA, TKDK

\footnotetext{
${ }^{1}$ Tarım ve Kırsal Kalkınmayı Destekleme Kurumu, MuhesebeUzmanı, kadir.bahtiyar@tkdk.org.tr
} 
An Evaluation of Rural Development: TKDK (Agriculture and Rural Development Support Agency) Example

\begin{abstract}
Agricultural policies in Turkey every year increases the importance of Rural Development. Constitutes an important part of agriculture in the economy which will be held in Turkey, especially rural support and investment in the EU level aims to achieve a strong rural development. Rural Development policies with the EU process has gained a new looking. EU, candidate countries gained the status of the countries of Agriculture and Rural Development aims at raising community standards of provision and provide financial aid and grants.

Agriculture and Rural Development's efforts to reach the community standards within the process has gained importance. EU member and candidate countries of Rural Development for the community to become compliant by allocating funds to these countries is accelerating this process. Agriculture and Rural Development Support Agency (TKDK), EU pre-accession financial assistance instrument IPA Rural Development component with Component 5 of the implementing agency was established in 2008. Institutions, with the funds generated by the EU and Turkey Korsak supports development investments are in the form of project-based grants. In this study TKDK and Turkey to put forward his contribution to rural development were studied.
\end{abstract}

Keywords: European Union, Rural Development, IPA, ARDSI

\title{
1. GİRIŞ̧
}

Kırsal Kalkınma, AB süreciyle birlikte Türkiye'de uyum çalışmaları içerisinde önem kazanmıştır. $\mathrm{Bu}$ uyum sürecinin takipuygulama ve koordine edilmesi görevi için yeni bir bakanlığın kurulması, ülkemizin AB'ye uyumu adına önemli adımlarından biri olmasının yanında sürece verdiği önemin de bir göstergesi olmuştur (Can ve Esengün, 2007). 35 fasıldan oluşan süreçte Türkiye için önemli bir yer teşkil eden "Tarım ve Kırsal Kalkınma" faslı da bulunmaktadır.

Türkiye'de Kırsal Kalkınma konusunda 8. Beş Yıllık Kalkınma Planı'nda ilk somut adımlar atılmaya başlanmıştır. AB süreciyle birlikte, kalkınma planlarında Kırsal Kalkınma artan bir ivmeyle yer almaya devam etmiştir (Can ve Esengün, 2007). Kırsalda verimli ve kaliteli üretimin gerçekleşmemesi, istihdam imkânlarının azlığı, kırsal tarım eğitiminin düşüklüğü, makineleşme yetersizliği, yatırım için gerekli 
sermaye yetersizliği ve bunların sonucunda gerçekleşen kente göç gibi problemlere bağlı olarak bu sorunların giderilmesine dönük çalışmalar başlıca Kırsal Kalkınma Politikaları haline gelmiştir (Günaydın, 2000; YPK, 2013; DPT, 2006).

Ülkemizde Tarım ve Kırsal Kalkınmanın topluluk standartlarına ulaştırılmasına yönelik çalışmalar süreç içerisinde önem kazanmıştır. Bu doğrultuda tarım sektöründe bir ilk olarak 21 Aralık 1999 tarihinde Tarımda Yeniden Yapılandırma ve Destekleme Kurulu teşkil edilmiştir (99/13759 say1lı Kararname). AB süreciyle birlikte ise üye ve aday ülkelerin Kırsal Kalkınmada topluluk standartlarına uyumlu hale gelmeleri için bu ülkelere verilen destek fonlarını değerlendirecek kurumlar oluşturulmuştur. Türkiye, aday statüsünde Kırsal Kalkınmaya sağlanan bu desteklerden yararlanmakta olup kırsala ait problemlerin giderilmesinde bu fonlardan azami ölçüde istifade etmesi büyük önem arz etmektedir. (www.tkdk.gov.tr). Bu makalede, kırsal tarımın geliştirilmesi ve kırsala ait problemlerin giderilmesi, $\mathrm{AB}$ standartlarında yatırımların hibeler yoluyla gerçekleştirilmesinde, IPARD (Instrument for Preaccession Rural Development) Programının uygulayıcı kurumu olarak faaliyet gösteren TKDK'nın etkisini ortaya koymak amaçlanmaktadır. Makale üç bölümden oluşmaktadır. İlk bölümde $\mathrm{AB}$ sürecinde, üye ve aday ülkelere Tarım ve Kırsal Kalkınmanın topluluk standartlarına ulaştırılması için sağlanan fonlar; ikinci bölümde IPARD Programı ve TKDK, ülkemizde kullanılan fonlar, bunların kullanıldığı yatırım alanları, hangi illerde ne seviyede yatırımların gerçekleştiği; üçüncü bölümde ise TKDK'nın tarım ve kırsal kalkınma çalışmalarının değerlendirilmesi ve karşılaşılan problemlere getirilebilecek öneriler ele alınacaktır.

\section{AB SÜRECİ YARDIM VE FONLARI}

Avrupa Birliği’nin temel finansman kaynağını oluşturan 3 temel öz kaynağı bulunmaktadır. Bunlar, geleneksel öz kaynaklar (temel olarak gümrük vergileri ile tarım ve şeker vergisi), KDV temelli gelirler ve üye ülkelerin gayri safi milli hâsılalarının bir bölümünü birliğe aktarmaları suretiyle oluşan gelirlerdir. Diğer gelir kaynakları ise; AB kurumlarının verdiği para cezaları, $\mathrm{AB}$ faaliyetlerinde elde edilen gelirler ve $\mathrm{AB}$ çalışanlarından yapılan kesintiler, üye ülke katkıları, özel ödemeler gibi gelirlerdir (Zülfüoğlu, 2011). 
$\mathrm{AB}$, bünyesinde bulundurduğu üye ülkelere ve aday konumundaki ülkelere, onları topluluğun gelişmiş̧lik seviyesinde belli standartlara yükseltmek ya da uyumlaştırmak amacıyla bu ülkelere ekonomik, sosyal bir takım yardımlar veya fonlardan istifade imkânı vermektedir. Bu yardım ve fonlar hibe ya da kredi şeklinde istendiğinde üye ya da aday olmasına bakılmaksızın başka ülkelere de verilebilmektedir. (Karataş, 2010; Karabacak, 2004). Bu bağlamda AB'nin mali yardımların 3 başlıkta incelemek mümkün olacaktır.

1-Üye ülkelere yapılan hibe ve yardımlar: $A B$, bütçesinin büyük bir bölümünü üye ülkelerin yapısal ve tarımsal harcamaları için kullanmaktadır. Bütçeden yapılan bu harcamalar komisyon tarafından denetlenmektedir. AB ortak tarım politikaları çerçevesinde başlangıçta bütçenin tamamına yakınını kullanırken zaman içerisinde bu oran yarıya düşmüştür (Bilici, 1997). AB'nin bölgesel politikaları gereği bölgeler arasındaki farklılıkların ortadan kaldırılması için yapısal fonlar kullanılmıştır (Karataş, 2010; Karabacak, 2004).

2-Üçüncü ülkelere yapılan yardım ve hibeler: AB'nin bütçe içerisinden üye ve aday olmayan ülkelere sağladığı yardımlardır (Güngör, 2000).

3-Aday ülkelere yapılan hibe ve yardımlar: AB'ye aday ülke statüsündeki ülkelere uyum ve uygulama süreci için sağlanan yardım ve fonlardır. 1999 Helsinki Zirvesi'yle adaylık statüsü kazanan ülkemiz de bu yardımlardan faydalanmıştır. Türkiye, 2001 yılından itibaren hibe olarak AB kaynaklarından mali yardım almaya başlamıştır. Bu hibeler ülkemizin $\mathrm{AB}$ 'ye uyumu sürecinde yasal ve kurumsal düzenlemeler için kullanılmıştır (Karataş, 2010; Karabacak, 2004).

Aday ve potansiyel aday ülkelere yönelik olarak yapılacak katılım öncesi yardımlar, mevcut hukuksal ve kurumsal altyapısının, $A B$ standartlarına ve uygulamalarına yakınlaştırılması ve uyumlaştırılmasını hedeflediğinden; demokratik kurumların ve hukukun üstünlüğü prensibinin güçlendirilmesi, ekonomik reformların gerçekleştirilmesi, insan haklarına saygı ilkesi, sivil toplumun ve bölgesel işbirliğinin güçlenmesinin desteklenmesi, sürdürülebilir kalkınma ve yoksulluğun azaltılması gibi konularda bu ülkelerin yapacağı çalışmalara destek vermeyi amaçlar ve bu yüzden genel olarak kurumsal yapılanma odaklıdırlar (Akın, 2008). 
2002-2006 y1lları arası Türkiye tarafindan kullanılan AB Mali Yardımları 1,320 milyon €'dur. Bu fonlar \% 30 kurumsal yapılanma, $\% 35 \mathrm{AB}$ müktesebatına uyum, \%35 ekonomik ve sosyal uyum için kullanılmıştır (www.ab.gov.tr).

Bunun yanı sıra adaylık statüsü kazanan Türkiye, 2000-2006 yılları arası aday ülkelere sağlanan PHARE, ISPA VE SAPARD programlarından istifade edememiştir. Zira bütçenin kesinleştiği ve değişikliğin mümkün olmadığı belirtilmiştir. Buna karşıllk MEDA II programı mali desteklerinden yararlanmıştır (www.abgs.gov.tr).

PHARE: (Coordinated Support for the Reconstructuring of Economics of Poland and Hungary - Polonya ve Macaristan Ekonomilerinin Yeniden Yapılandırılmasına Yönelik Destek Programı) $\mathrm{Bu}$ program Merkez ve Doğu Avrupa ülkelerinde bu devletlerin ekonomilerini yeniden yapılandırma çabalarını desteklemek amacıyla oluşturulmuştur. 1994'te yalnızca Polonya ve Macaristan'a yönelik olarak tasarlanan program Arnavutluk, Bosna-Hersek, Bulgaristan, Çek Cumhuriyeti, Estonya, Letonya, Litvanya, Makedonya, Macaristan, Polonya, Romanya, Slovakya, Slovenya'yı da kapsayacak biçimde genişletilmiştir (Çeliktaş, 2006; Bakırcı, 2009 ).

PHARE programı, AB'ye üye olmak için başvuran Merkezi Doğu Avrupa Ülkeleri için üyelik öncesi strateji kapsamında kullanılan temel mali araçtır ve destek alanları bu ülkelerin öncelik ve gereksinimlerine göre belirlenmiştir (Karabacak, 2004). Kurumsal yapılanma ve topluluk müktesebatına uyuma yönelik desteklerin bu program kapsamında yapılması bu programı önemli kılmaktadır. Enerji, ulaştırma ve haberleşme altyapısı; özel sektörün gelişimi ve işletmelerin desteklenmesi; eğitim, mesleki eğitim ve araştırma; çevrenin korunması ve nükleer güvenlik; tarımsal yapıların yeniden düzenlenmesi gibi sektörlerde destek verilmiştir.

ISPA: (Instrument for Structural Policies for Pre-AcessionKatılım Öncesi Yapısal Politika Aracı) AB adayı Merkez ve Doğu Avrupa ülkelerine adaylık sürecinde çevre ve ulaştırma alanlarında mali destek sağlamaya yönelik bir programdır. $\mathrm{AB}$ mevzuatına uygun çevre şartlarının sağlamasını ve AB standartlarına erişilmesini hedefleyen ISPA kapsamında çevrenin korunması, çevre kalitesinin iyileştirilmesi, çevre sağlığ1 ve doğal kaynakların korunması öncelikli alan olarak belirlenmiştir (Çeliktaş, 2006; Bakırcı, 2009). 
Ulaşım alanında ise aday ülkelerin altyapılarının iyileştirilerek, $\mathrm{AB}$ ulaşım ağlarına bağlanması öngörülmektedir. Aday ülkelerin transAvrupa kara ulaşım ve demiryolu ağları ile bağlantılarının ve ulusal ağlar arasındaki ara bağlantıları sağlayacak projeler finanse edilmektedir ISPA programından yararlanan ülkeler Bulgaristan, Çek Cumhuriyeti, Estonya, Macaristan, Letonya, Litvanya, Polonya, Romanya, Slovakya ve Slovenya'dır (Başarır, 2008; Çeliktaş, 2006).

CARDS: (Community Assistance to Reconstruction Development and Stability -Yeniden Yapılanma, Kalkınma ve İstikrar İçin Birlik Yardımı) CARDS Programı ile Arnavutluk, Bosna Hersek, Hırvatistan, Yugoslavya ve Makedonya'da, bölgesel ve uluslararas1 ticaretin artırılması, ulaşım, enerji ve çevre sorunları, azınlık haklarının korunması, sivil toplumun güçlendirilmesi, kamu kurumları arasında işbirliğinin artırılması, sınır ötesi suçların azaltılması konularında bölgesel çözümler üretilmesi hedeflenmiştir. Ayrıca altyapı hizmetlerinin geliştirilmesi, ekonomik yeniden yapılanmanın ve demokratikleşmenin sağlanması amaçlanmıştır (Bilici, 1997; Bakırc1, 2009).

SAPARD: (Special Accession Programme for Agriculture and Rural Development -Tarım ve Kırsal Kalkınma İçin Özel Katılım Programı) SAPARD programı AB'ye katılımlarından önce Merkezi Doğu Avrupa Ülkelerinin tarım ve kırsal kalkınma alanlarında Topluluğun tarım politikası müktesebatına uyum sağlamalarına katkıda bulunmayı amaçlamaktadır. 2000 yılında başlayan program, tarım reformları kapsamında, bu ülkelerin ortak tarım politikası ve tek pazar konularında hazırlıklarını desteklemek amacıyla tasarlanmıştır. SAPARD MDA ülkelerinin ulusal kırsal kalkınma programlarına Birlik bütçesinden eş finansman desteği de sağlamıştır. SAPARD, AB kaynaklarının hem de aday ülkelerin ulusal kaynaklarının oluşturduğu fonlarla 2000-2006 döneminde kırsal kalkınma amaçlı olarak hazırlanan projelere katk1 sağlayan fon programı olmuştur (www.zmo.org.tr).

SAPARD kapsamında merkezi olmayan yapılanma öngörülmüş olup, projelerin yönetimi gerekli yapının kurulması şartıyla aday ülkeye devredilmiştir. 1 Mayıs 2004 tarihinde AB'ye üye olan Çek Cumhuriyeti, Estonya, Letonya, Litvanya, Macaristan, Slovenya, Slovakya, Polonya bu tarihten itibaren katılım öncesi fonlardan daha fazla faydalanamamışlardır (Bilici, 2010). 
Helsinski Zirvesinde Türkiye'nin Avrupa Birliği adaylığının teyit edilmesiyle yeni bir döneme girilmiş ve bu gelişme Türkiye'ye sağlanan mali yardımın niteliği ve miktarında değişikliğe sebep olmuştur. Avrupa Birliği bu süreçte Türkiye'nin diğer aday ülkelerle eşit koşullarda yer alacağını belirterek 17 Aralık 2001 tarih ve 2500/2001 sayılı Konsey Tüzüğü (Çerçeve Anlaşma) ile Türkiye'ye yapılacak hibe niteliğindeki mali yardımları tek bir çerçeve altında toplamıştır (www.ikv.org.tr).

2005 y1lında Türkiye'nin AB üyelik müzakerelerine başlamasıyla $A B$ 'den sağladığı mali yardımların şekli ve miktarı da değişmiştir. 20072013 yıllarına için aday ülkelere mali yardımlar IPA Katılım Öncesi Mali Yardımlar başlığı altında yapılmaya başlanmıştır (2500/ 2001 sayılı Konsey Tüzüğü). AB, IPA çerçevesinde 2007-2013 dönemi için yaklaşı 10 milyon $€$ fon ayırmıştır. IPA, Geçiş Dönemi ve Kurumsal Yapılanma, Sınır Ötesi İşbirliği, Bölgesel Kalkınma, İnsan Kaynaklarının Geliştirilmesi, Kırsal Kalkınma (IPARD) şeklinde beş alt başlıkta mali yardım bileşenleri belirlemiştir (www.mfa.gov.tr).

Tablo 1: 2007-2013 IPA Fonlarının Aday ve Potansiyel Aday Ülkelere Dağılımı (Milyon $€$ )

\begin{tabular}{|l|c|}
\hline ÜLKE & $\mathbf{2 0 0 7 - 2 0 1 3}$ \\
\hline Hirvatistan & 1.000 \\
\hline Makedonya & 619 \\
\hline Türkiye & 4.831 \\
\hline Arnavutluk & 597 \\
\hline Bosna Hersek & 658 \\
\hline Karadă & 236 \\
\hline Sirbistan & 1.392 \\
\hline Kosova & 637 \\
\hline İzlanda & 30 \\
\hline TOPLAM & $\mathbf{1 0 . 0 0 0}$ \\
\hline
\end{tabular}

Kaynak: www.abgs.gov.tr

Tablo 1'de fonların aday ve potansiyel aday ülkeler için dağglımı verilmiştir. Ülkelere tahsis edilen fonlar içerisinde nüfusu ve yüzölçümü dikkate alınarak en fazla payın -toplam fonun yarısına yakınınınTürkiye'ye ayrıldı̆̆ı görünmektedir. 
Tablo 2: IPA Dönemi 2007-2013 Türkiye Mali Yardımları Bileşen Tahsisi (Milyon $€$ )

\begin{tabular}{|l|c|c|c|c|c|c|c|c|}
\hline BİLEŞEN & $\mathbf{2 0 0 7}$ & $\mathbf{2 0 0 8}$ & $\mathbf{2 0 0 9}$ & $\mathbf{2 0 1 0}$ & $\mathbf{2 0 1 1}$ & $\mathbf{2 0 1 2}$ & $\mathbf{2 0 1 3}$ & Toplam \\
\hline $\begin{array}{l}\text { Geçiş Dönemi } \\
\text { ve Kurumsal } \\
\text { Yapılanma }\end{array}$ & 256,7 & 256,1 & 239,6 & 217,8 & 231,3 & 227,5 & 238,5 & $1.667,5$ \\
\hline $\begin{array}{l}\text { Sinır Ötesi } \\
\text { İşbirliği }\end{array}$ & 2,1 & 2,9 & 3 & 3,1 & 5,1 & 2,2 & 2,2 & 20,6 \\
\hline $\begin{array}{l}\text { Bölgesel } \\
\text { Kalkınma }\end{array}$ & 167,5 & 173,8 & 182,7 & 238,1 & 293,4 & 356,1 & 366,9 & $1.778,4$ \\
\hline $\begin{array}{l}\text { İnsan } \\
\text { Kaynaklarının } \\
\text { Geliştirilmesi }\end{array}$ & 50,2 & 52,9 & 55,6 & 63,4 & 77,6 & 83,2 & 91,2 & 474,1 \\
\hline $\begin{array}{l}\text { Kırsal } \\
\text { Kalkınma }\end{array}$ & 20,7 & 53 & 85,5 & 131,3 & 172,5 & 189,78 & 213 & 865,78 \\
\hline Toplam & 492,2 & 538,7 & 566,4 & 653,7 & 779,9 & 858,8 & 911,8 & $\mathbf{4 . 8 0 6 , 3 8}$ \\
\hline
\end{tabular}

Kaynak: www.abgs.gov.tr

Tablo 2'de bileşenlere göre fon tahsisi verilmiştir. IPA kapsamındaki mali yardımlardan faydalanabilmek için, yararlanıcı ülkenin gerekli idari yapıları oluşturması zorunludur. Bu idari yapıların neler olduğu ve fonksiyonları ise, IPA'nın uygulama kurallarını belirten 718/2007 sayılı IPA Uygulama Tüzüğü'nde açıklanmaktadır. Türkiye, bu yeni mali yardım mekanizmasının işleyişini düzenlemek üzere Avrupa Komisyonu ile 2008 yılında bir IPA Çerçeve Anlaşması akdetmiştir. Ayrıca bu anlaşma gereğince, Merkezi Olmayan Yapılanmanın IPA usül ve esaslarına uygun olarak yeniden düzenlenmesi amacıyla 2009/18 sayılı Başbakanlık genelgesi yayımlanmıştır.

IPARD fonlarının kullanılabilmesi için IPARD Programının uygulayıcısı olarak diğer bileşenlerden farklı olarak IPARD Ajansı'nın kurulması gerekli olup, bu amaçla 18.05.2007 tarihinde 5648 Sayılı kanun ile Tarım ve Kırsal Kalkınmayı Destekleme Kurumu kurulmuştur (26526 say1l RG, 2007)

\section{TÜRKIYY'NINN ADAYLIK SÜRECİNDE TKDK}

Gıda Tarım ve Hayvancılık Bakanlığı'nın ilgili bir kurumu olan TKDK, IPA beşinci bileşeni olan IPARD Kırsal Kalkınmanın 
Desteklenmesi amaçlı fonların kullanımına ait tüm yetkileri AB'den 2008 yılında devralmıştır. TKDK'nın Avrupa Komisyonu ve Türkiye Cumhuriyeti tarafından oluşturulan bu fonları "Tarım sektörünün etkinliğinin ve rekabet gücünün arttırılması suretiyle adaptasyonun sağlanması ve Topluluk standartlarının uygulanması" amaçlı olarak kullandırtması planlanmıştır.

TKDK teşkilat yapısı olarak IPARD harcamalarıyla alakalı olarak;

Ödeme görevleri olarak taahhüt ve ödemelerin izin ve kontrolü ile ödemelerinin yapılması, taahhüt edilmiş ve ödenmiş IPARD harcama hesaplarının tutulması, Avrupa komisyonu için harcama özetlerinin çıkarılması, hazine görevi olarak ise banka hesaplarının düzenlenmesi, fon talep edilmesi, alınan fonların TKDK veya nihai yararlanıcılara aktarılmasına izin verilmesi görevlerini yerine getirir. (IPARD Mevzuatı Sektörel Anlaşma, 2012).

Uygulama görevleriyse, IPARD programı için gerekli kriter, mekanizmalar ve kurallar ile uyumlu operasyonları seçmek, sözleşme yükümlülüklerini ve bunlara uyulmamasının yaptırımlarını anlatmak, Avrupa birliğinin rolünü ve yardımların şeffaflığının tanıtımın yapmak, IPARD harcamasının mevzuata ve usule uygunluğu, usulsüzlüğ̈̈n teşhisi ve derhal bildirilmesi konusunda güvence vermektir (IPARD Mevzuat1 Sektörel Anlaşma, 2012).

TKDK bu görevlerin yanında başvuru çağrısını düzenler ve yapar, IPARD gereği uygun operasyonları seçme ve uygulamayla ilgili olarak Avrupa ve ulusal kuralların uyumunu sağlar; yapılan başvuruların anlaşmalara uygunluğunu kontrol eder; sözleşme hükümlerinin yerine getirilmemesi durumunda uygulanacak müeyyideleri ilişkin bilgileri ortaya koyar; hibe programlarının uygulanmasını düzenleme ve sözleşme yapa; yararlanıcıya ödeme yapar ve geri alımı gerçekleştirir. Proje kabulü öncesi ve sonrası yerinde denetim yapar; beyan edilen harcamanın geçerli 
kurallar dâhilinde yapıldığını idari, teknik ve fiziksel açıdan yapar; projelerin ve tedbirlerin uygulanmasının göstergeler yoluyla takibi ve raporlanmas1, yararlanıcının $\mathrm{AB}$ katkısı hususunda bilgilendirilmesi, usulsüzlüklerin raporlanması, ulusal yetkilendirme, ulusal fon ve yönetim otoritesine gerekli bilgileri vermek görevlerini de yerine getirir (Sektörel Anlaşma Md. 14)

IPARD programıla hedeflenen ise Tarım Sektörünün sürdürülebilir modernizasyonunu sağlamak, gıda güvenliği, veterinerlik, bitki sağlı̆̆ 1 , çevre ve diğer standartlara ilişkin $\mathrm{AB}$ standartlarına ulaşmasının teşvik edilmesi, kırsal alanların sürdürülebilir kalkınmasına katk1 sağlanması, yerel kırsal kalkınma stratejileri ve tarım-çevre tedbirlerinin uygulanması için hazırlık faaliyetlerinin yapılmasıdır (IPARD Yatırımcı Rehberi, 2013).

TKDK bu fonları, Türkiye'nin topluluk standartlarında bir Tarım ve Kırsal Kalkınma sağlaması çerçevesinde Kalkınma programımıza uygun olarak kullandırtmayı hedeflemiştir. Kurum, çalışmalarına 2008 yılında tablo 3 te gösterilen 1.fazda 20 ille başlamış, sonra bu illere 2. faz olarak 2012 y1lında tablo 3 te gösterilen 22 il daha eklenmiş ve toplam 42 il koordinatörlügüüyle çalışmalarına devam etmektedir (tkdk.gov.tr).

Tablo 3: TKDK İl Koordinatörlükleri

\begin{tabular}{|l|l|}
\hline \multirow{3}{*}{ Faz İller } & Afyonkarahisar, Amasya, Balıkesir, Çorum, Diyarbakır, \\
& $\begin{array}{l}\text { Erzurum, Hatay, Isparta, Kahramanmaraş, Kars, Konya, } \\
\text { Malatya, Ordu, Samsun, Sivas, Şanlıurfa, Tokat, Trabzon, Van, } \\
\text { Yozgat, }\end{array}$ \\
\hline \multirow{3}{*}{ Faz İller } & $\begin{array}{l}\text { Ağrı, Ankara, Aksaray, Ardahan, Aydın, Burdur, Bursa, } \\
\text { Çanakkale, Çankırı, Denizli, Elazı̆̆, Erzincan, Giresun, } \\
\text { Karaman, Kastamonu, Kütahya, Manisa, Mardin, Mersin, Muş, } \\
\text { Nevşehir, Uşak }\end{array}$ \\
\hline
\end{tabular}

Kaynak: tkdk.gov.tr

IPARD Programı IPA Tüzügü ve IPA Uygulama Tüzügü çerçevesinde hazırlanmıştır. Genel amacı Tarım sektörünün etkinliğinin ve rekabet gücünün arttırılması suretiyle adaptasyonunun sağlanması ve Topluluk 
Standartlarının uygulanması olan 3 eksende, Türkiye eksen-1 ve eksen3 'te yer alan tedbirlere fon tahsisi yapabilmektedir.

Tablo 4: Türkiye'de Fon Tahsisi Yapılabilecek Eksen ve Tedbirler

\begin{tabular}{|l|l|l|}
\hline \multicolumn{1}{|c|}{ Eksen 1 } \\
$\begin{array}{l}\text { Tarım ve Ormancılık } \\
\text { Sektörlerinde Rekabet } \\
\text { Edebilme Yeteneğinin } \\
\text { Geliştirilmesi }\end{array}$ & $\begin{array}{c}\text { Eksen 2 } \\
\text { Arazi Yönetimi ve } \\
\text { Kırsal Çevrenin } \\
\text { Iyileştirilmesi }\end{array}$ & $\begin{array}{l}\text { Eksen 3 } \\
\text { Kirsal Alanlarda Yaşam } \\
\text { Kalitesinin ve Ekonomik } \\
\text { Çeşitliliğin Geliştirilmesi }\end{array}$ \\
\hline $\begin{array}{l}\text { 101-Tarımsal işletmelerin } \\
\text { Yeniden Yapılandırılması ve } \\
\text { Topluluk Standartlarına } \\
\text { Ulaştırılmasına Yönelik } \\
\text { Yatırımlar }\end{array}$ & & $\begin{array}{l}\text { 302-Kırsal Ekonomik } \\
\text { Faaliyetlerin } \\
\text { Çeşitlendirilmesi ve } \\
\text { Geliştirilmesi }\end{array}$ \\
\hline $\begin{array}{l}\text { 103-Tarım ve Balıçılık } \\
\text { Ürünlerinin } \\
\text { Isşlenmesi ve Pazarlanmasının } \\
\text { Yeniden Yapılandırılması ve } \\
\text { Topluluk Standartlarına }\end{array}$ & & \\
Ulaştırılmasına Yönelik & & \\
Yatırımlar & & \\
\hline
\end{tabular}

Kaynak: Bilici, 2010

Bunun sonucu olarak Tablo 4'te gösterildiği üzere Türkiye'de sadece eksen-1'den 101 Tarımsal işletmelerin Yeniden Yapılandırılması ve Topluluk Standartlarına Ulaştırılmasına Yönelik yatırımlar ve 103 Tarım ve Balıkçılık Ürünlerinin İşlenmesi ve Pazarlanmasının Yeniden Yapılandırılması ve Topluluk Standartlarına Ulaştırılmasına Yönelik Yatırımlar tedbirlerine, eksen-3 başlığı altında ise sadece $302 \mathrm{Kırsal}$ Ekonomik Faaliyetlerin Çeşitlendirilmesi ve Geliştirilmesi tedbirine yatırım imkânı söz konusudur.

Tablo 5'te görüldüğü üzere tedbirler kendi içinde alt tedbirlere ayrılmakta ve bu alt tedbirlere göre farklı sektörlere yatırım yapılması imkânı sağlanmaktadır. Tedbirlere tahsis edilen fon miktarları belirli sınırlar dâhilinde kullandırtılmaktadır. Her tedbir için sağlanan destek miktarı farklı1ık arz etmektedir. Kurum Koordinatörlükleri bulundukları ilde IPARD Programı kapsamında belirlenmiş Kırsal Kalmayı sağlayacak her tedbire ait yatırıma imkân sağlamaktadır.

302 Kursal Ekonomik Faaliyetlerin Çeşitlendirilmesi ve Geliştirilmesi tedbiri kapsamındaki yatırımların kırsal alanda gerçekleştirilmesi gerekmektedir. Kırsal alan nüfusu 20.000'den az olan yerleşim yerlerini, dağlık alan ise 1000 metre rakımdan yüksek ya da 
rakımı 500-1000 metre arasında olup eğimi \%17'den fazla olan alanları ifade etmektedir (www.tkdk.gov.tr).

TKDK fonların kullanılmasında diğer bir husus, belirlenmiş uygun ve uygun olmayan harcamalar ayırımıdır. Kurum bu harcamalardan uygun olanlara destek vermektedir (TKDK Başvuru Rehberi, 2014). Kurum tarafindan kullandirilacak olan bu fonlar \%75 AB katkıs1, \%25 Türkiye Cumhuriyeti katkısı ile oluşur.

Kurum koordinatörlüklerinin bulunduğu ilde destek verilen bu tedbirlere gerçek veya tüzel kişiler gerekli şartları sağlayarak başvuruda bulunabilir. Kurumun çağrı ilanına çıkmasıyla bu fonların kullandırtılması süreci başlamış olur. Hazırlık aşamasını tamamlayıp projesini hazırlayarak kuruma başvuruda bulunan ve başvurusu, kurumca belirli seçim kriterlerine göre yapılan inceleme- kontrol sonucu kabul edilen başvuru sahibi, faydalanıcı sıfatını kazanır. Kurum, başvurusu kabul edilen faydalanıcıyla sözleşme yapar ve yatırım süreci fiili olarak başlamış olur. Sözleşmede yatırıma ait karşılıklı tüm yükümlülük ve görevler belirtilir. Kurum, yatırımın sözleşme şartlarına uygun sürdürülüp sürdürülmediğini uzmanları eliyle kontrol eder ve raporlar. Kurumca yapılan tüm kontroller doğrultusunda yatırımın sözleşemeye uygun bir şekilde tamamlandığ 1 , hazırlanan raporlarda belirtilir. Faydalanıcı hazırladığ harcamaları talep eder. Kurum, harcama belgeleri üzerinden yaptığ 1 kontroller sonucu ödenmesi gereken miktarı belirler ve en geç 3 ay içerisinde faydalanıı hesabına aktarır (TKDK Başvuru Rehberi, 2014). 
Tablo 5: Tedbirler ve Hibe Miktarları

\begin{tabular}{|c|c|c|c|c|}
\hline \multirow{3}{*}{$\begin{array}{c}\text { 101-Tarımsal } \\
\text { İşletmelerin } \\
\text { Yeniden } \\
\text { Yapılandırılması ve } \\
\text { Topluluk } \\
\text { Standartlarına } \\
\text { Ulaştırılmasına } \\
\text { Yönelik Yatırımlar } \\
\text { (Destek Oranı } \\
\text { \%50-65) }\end{array}$} & \multicolumn{2}{|c|}{$\begin{array}{l}\text { 101-1 Süt Üreten Tarımsal } \\
\text { İşletmelere Yatırım }\end{array}$} & \multirow{2}{*}{$\begin{array}{c}15.000 €- \\
1.000 .000 € \\
20.000 €- \\
1.000 .000 €\end{array}$} & \multirow{13}{*}{$\begin{array}{c}\text { Afyonkarahisa } \\
\text { Ağrı } \\
\text { Aksaray } \\
\text { Amasya } \\
\text { Ankara } \\
\text { Ardahan } \\
\text { Aydın } \\
\text { Balıkesir } \\
\text { Burdur } \\
\text { Bursa } \\
\text { Çanakkale } \\
\text { Çankırı } \\
\text { Çorum } \\
\text { Denizli } \\
\text { Diyarbakır } \\
\text { Elazı̆ } \\
\text { Erzincan } \\
\text { Erzurum } \\
\text { Giresun } \\
\text { Hatay } \\
\text { Isparta } \\
\text { K.maraş } \\
\text { Karaman } \\
\text { Kars } \\
\text { Kastamonu } \\
\text { Konya } \\
\text { Kütahya } \\
\text { Malatya } \\
\text { Manisa } \\
\text { Mardin } \\
\text { Mersin } \\
\text { Muş } \\
\text { Nevşehir } \\
\text { Ordu } \\
\text { Samsun } \\
\text { Sivas } \\
\text { Şanlıurfa } \\
\text { Tokat } \\
\text { Trabzon } \\
\text { Uşak } \\
\text { Van } \\
\text { Yozgat }\end{array}$} \\
\hline & \multirow{2}{*}{$\begin{array}{l}\text { 101-2 Et Üreten } \\
\text { Tarımsal } \\
\text { İşletmelere } \\
\text { Yatırım }\end{array}$} & Kirmız1 et & & \\
\hline & & Beyaz et & $\begin{array}{l}15.000 €- \\
500.000 €\end{array}$ & \\
\hline \multirow{6}{*}{$\begin{array}{c}\text { 103-Tarım ve } \\
\text { Balıkçılık } \\
\text { Ürünlerinin } \\
\text { İşlenmesi ve } \\
\text { Pazarlanmasının } \\
\text { Yeniden } \\
\text { Yapılandırılması ve } \\
\text { Topluluk } \\
\text { Standartlarına } \\
\text { Ulaştırılmasına } \\
\text { Yönelik Yatırımlar } \\
\text { (Destek Oranı } \\
\text { \%50) }\end{array}$} & \multirow{2}{*}{$\begin{array}{l}\text { 103-1 Süt ve Süt } \\
\text { Ürünlerinin } \\
\text { İşlenmesi ve } \\
\text { Pazarlanmas1 }\end{array}$} & $\begin{array}{c}\text { Süt } \\
\text { işleme } \\
\text { tesisleri }\end{array}$ & $\begin{array}{c}50.000 €- \\
3.000 .000 €\end{array}$ & \\
\hline & & $\begin{array}{c}\text { Süt } \\
\text { toplayan } \\
\text { üretici } \\
\text { örgütleri }\end{array}$ & $\begin{array}{c}25.000 €- \\
1.000 .000 €\end{array}$ & \\
\hline & \multirow{2}{*}{$\begin{array}{c}\text { 103-2 Et ve Et } \\
\text { Ürünlerinin } \\
\text { İşlenmesi ve } \\
\text { Pazarlanmas1 }\end{array}$} & Kırmız1 et & $\begin{array}{c}30.000 €- \\
3.000 .000 €\end{array}$ & \\
\hline & & Beyaz et & $\begin{array}{c}30.000 €- \\
3.000 .000 €\end{array}$ & \\
\hline & $\begin{array}{l}\text { 103-3 Meyve ve } \\
\text { Sebzelerin } \\
\text { İşlenmesi ve } \\
\text { Pazarlanmas1 }\end{array}$ & & $\begin{array}{c}50.000 €- \\
1.250 .000 €\end{array}$ & \\
\hline & $\begin{array}{c}\text { 103-4 Su } \\
\text { Ürünlerinin } \\
\text { İşlenmesi ve } \\
\text { Pazarlanmas1 }\end{array}$ & & $\begin{array}{c}50.000 €- \\
1.500 .000 €\end{array}$ & \\
\hline \multirow{4}{*}{$\begin{array}{c}\text { 302-Kırsal } \\
\text { Ekonomik } \\
\text { Faaliyetlerin } \\
\text { Çeşitlendirilmesi } \\
\text { ve } \\
\text { Geliştirilmesi } \\
\text { (DestekOranı\%50) }\end{array}$} & $\begin{array}{c}\text { 302-1 Çiftlik } \\
\text { Faaliyetlerinin } \\
\text { Çeşitlendirilmesi } \\
\text { ve Geliștirilmesi }\end{array}$ & \multicolumn{2}{|c|}{$5.000 €-250.000 €$} & \\
\hline & $\begin{array}{l}\text { 302-2 Yerel } \\
\text { Ürünlerin ve } \\
\text { Mikro } \\
\text { İşletmelerin } \\
\text { Geliştirilmesi }\end{array}$ & \multicolumn{2}{|c|}{$10.000 €-400.000 €$} & \\
\hline & $\begin{array}{l}\text { 302-3 Kırsal } \\
\text { Turizm }\end{array}$ & \multicolumn{2}{|c|}{$15.000 €-500.000 €$} & \\
\hline & $\begin{array}{l}\text { 302-4 Kültür } \\
\text { Balıkçıllı̆ıının } \\
\text { Geliştirilmesi }\end{array}$ & \multicolumn{2}{|c|}{$15.000 €-400.000 €$} & \\
\hline
\end{tabular}

Kaynak: www.tkdk.gov.tr

Faydalanıcıya ödemenin yapılmasıyla fiziki kapanış gerçekleşmiş olur. Bundan sonraki süreç uygulama sonrası süreç olarak 
değerlendirilecek ve kurum 5 yıl süreyle yatırımın sürdürülebilirliğini kontrol edecektir. Kurumun bu 5 yıllık kontrolleri sonunda faydalanıcinın kurumla hiçbir bağlantısı kalmayacaktır (TKDK Başvuru Rehberi, 2014).

\subsection{TKDK Kırsal Kalkınma Destekleri}

TKDK 1. faz illerle 2012 yılında fonları desteğe dönüştürmeye başlamış 2. Faz illerin akredite olup sürece dâhil olmasıyla fonlar daha hızlı bir şekilde ve artan bir ivmeyle yatırıma dönüştürülmüştür. Kurum 2014 Nisan itibariyle 12 çağrıya çıkmış bulunmakta olup toplam 11 çağrı neticelenmiştir. Her çağrı döneminde gerek başvuru sayısı gerekse yapılan sözleşme sayısında buna bağlı olarak gerçekleşen yatırım tutarında dikkat çeken bir artı̧s söz konusudur. Özellikle akredite olan il sayısındaki artış proje sayılarının ve kullandırtılan fon miktarının ciddi oranlarda yükselmesine sebep olmuştur. 11. çağrı sonunda toplam 3.090 proje hayata geçirilmiş ve bunun karşıllı̆̆ında 790.618.612,16 TL destek gerçekleşmiştir (www.tkdk.gov.tr). $\mathrm{Bu}$ rakamın sadece $\mathrm{AB}$ ve Türkiye katkısıyla yatırımın \% 50 si şeklinde elde edilen rakamlar olup diğer \%50'nin yatırımcı tarafından finanse edildiğini düşündüğümüzde toplam yatırımın iki katına çıkacağı ve 1,5 trilyon TL'yi aşacağı hesaplanabilir.

IPA fonlarının ilgili yılı izleyen 3 yıl içerisinde ( $n+3$ kuralı) kullanılması mümkün olmaktadır. Dolayısıyla Kurum 2013 yılına ait fonlarını 2016 ya kadar kullandırtma imkânına sahiptir. Kurum son yıllarda göstermiş olduğu performans ile bu fonları bu süre içerisinde desteğe dönüştürme çabasını devam ettirmektedir (Bilici, 2010).

Tablo 6: Çağrılar ve Katkı Oranları

\begin{tabular}{|c|c|c|c|c|}
\hline $\begin{array}{c}\text { Çağrı } \\
\text { Dönemi }\end{array}$ & $\begin{array}{c}\text { Sözleşmeye } \\
\text { Bağlanan } \\
\text { Proje Sayısı }\end{array}$ & AB Katkısı & T.C. Katkısı & $\begin{array}{c}\text { TKDK desteği } \\
\text { (D+E) }\end{array}$ \\
\hline 1 & 4 & $873.862,50$ & $291.287,50$ & $1.165 .150,00$ \\
\hline 2 & 58 & $36.834 .495,98$ & $12.278 .165,33$ & $49.112 .661,30$ \\
\hline 3 & 91 & $54.825 .583,70$ & $18.275 .194,57$ & $73.100 .778,27$ \\
\hline 4 & 52 & $23.158 .807,72$ & $7.719 .602,57$ & $30.878 .410,29$ \\
\hline 5 & 46 & $23.684 .049,54$ & $7.894 .683,28$ & $31.578 .732,82$ \\
\hline 6 & 44 & $26.547 .723,40$ & $8.849 .241,44$ & $35.396 .964,84$ \\
\hline 7 & 43 & $776.089,47$ & $258.696,50$ & $1.034 .785,97$ \\
\hline 8 & 111 & $51.740 .491,77$ & $17.246 .831,24$ & $68.987 .323,01$ \\
\hline 9 & 981 & $200.763 .532,60$ & $66.921 .181,16$ & $267.684 .713,76$ \\
\hline 10 & 417 & $58.948 .567,88$ & $19.649 .523,88$ & $78.598 .091,76$ \\
\hline 11 & 1.243 & $114.832 .439,66$ & $38.277 .482,48$ & $15.308 .1000,14$ \\
\hline Toplam & $\mathbf{3 . 0 9 0}$ & $\mathbf{5 9 2 . 9 8 5 . 6 4 4 , 2 2}$ & $\mathbf{1 9 7 . 6 6 1 . 8 8 9 , 9 5}$ & $\mathbf{7 9 0 . 6 1 8 . 6 1 2 , 1 6}$ \\
\hline
\end{tabular}

Kaynak: tkdk.gov.tr 
Tablo 6'da göründügü üzere kurumun uygun harcama olarak hibe desteği verdiği uygun harcamalar, yapım ve inşaat işleri, makine ekipman alımı, hizmet alımı ve görünürlük harcamalarıdır.

\section{DEĞERLENDİRME VE SONUÇ}

Kırsal Kalkınma politikalarının ülkemizde tatbikinde kırsalda yaşayan halkın sürece aktif katılımının sağlanamaması politikaların başarı şansını azaltmıştır. AB süreciyle kırsala sağlanan destekler sayesinde Kırsal kalkınmanın sağlanmasında Kurum ve kırsaldaki halkın birlikteliği bu problemin çözümü adına önemli bir adım olmuştur. TKDK'nın kırsaldaki destekleriyle gerçekleşen Kırsal yatırımların her geçen yıl ve çağrıda artış gösterdiği gözlenmektedir. Bu aynı zamanda kırsal-devlet birlikteliğinin artması manasına gelmektedir. Zira bu çalışmalar halk tarafından "ayağımıza kadar gelen devlet" şeklinde algılanmaktadır.

Kırsal Kalkınmanın sağlanması politikaları geliştirildikçe buna ayrılan bütçe de artış göstermektedir. Tarım sektörünün çok önemli olduğu ülkemizde Kırsal kalkınma büyük bütçeler gerektirmektedir. AB'nin sağlamış olduğu bu hibe fonları Kırsal kalkınma bütçesine katkı sağlamaktadır. AB fonlarının ülkemize girişini arttıracak yeni tedbirlerin ve yatırım alanlarının oluşturulması gerekmektedir. Öncelikle Kurumun her ilde faaliyet gösterir hale getirilmesi gerekmektedir.

Başta büyükşehirler olmak üzere yerel yönetimlerin kurumla irtibatının çok iyi sağlanması, kurumun sağlamakta olduğu bu kaynakların kırsalın geliştirilmesine sevkinde işbirliği içinde olunması önem arz etmektedir. Kırsalda yatırımın artması yerel yönetimlere düşen görevler kurumun çalışmalarıyla yerine getirilmiş olmaktadır.

Kurumun aracı olduğu yatırımların değerlendirilmesine yönelik tanıtım çalışmaları sadece kurum ölçeğinde kalmamalıdır. Kurumun kırsalda tanınması ve başvuruların artması daha etkin bir tanıtım çalışmasıyla mümkün olabilir.

Gerek kurumun ülke geneline yayılması gerek yapılan yatırımlar sayesinde önemli bir istihdam oluşturulacaktır. Kırsal alt yapının geliştirilmesi, çevre, kırsal eğitim gibi önemli başlıkların da projelendirilmesi önem arz etmektedir.

Başvuru koşullarının esnetilerek daha fazla başvurunun sağlanması da önemlidir. Başvuru şartları ve bunların sağlanması zaman alıcı olmanın yanında yatırımcıya mali külfet getirmektedir. Diğer üye 
ülkelerdeki asgari başvuru şartlarının Türkiye'de uygulanır hale gelmesi bu süreyi daha da kısaltacaktır.

Süreç içerisindeki bürokratik işlemlerin kolay halledilebilir hale getirilmesi yine başvuru sayısının artırılmasında önemli olacaktır. Kurumun, 22 kamu kurum ve kuruluşu ile yapmış olduğu protokoller süreci hızlandırmıştır. Ancak sistemin tam tanınmamış olması bazı aksaklıkları beraberinde getirmektedir.

Yerel idarelerin belli yatırımlarda başvuru imkânını elde edebilmesi sağlanabilirse Kırsalda ihtiyaç duyulan birçok yatırım bu imkânlarla gerçekleşebilir. Bunun mümkün olması için başvuru şartlarının değiştirilerek yerel yönetimlerin başvuru yapabilmelerinin önünün açılması gerekmektedir.

Yapılan yatırıma ait harcamaların finansmanında yatırımcılara ön ödeme yapılması yoluyla rahatlatılması, sermaye birikimi olmayan kırsal halkı yatırma sevk edecektir. Her ne kadar ödemeler dönemler halinde yapılmaktaysa da daha lokal yatırım ve ödeme dengesi yatırımciyı rahatlatabilecektir.

Sanayi bölgelerinin sürece daha aktif dâhil edilmesi, koordinatörlük bulunan her ilde sanayi bölgeleri sürece dâhil edilmeli ve burada yatırım cazip hale getirilmelidir. Kurum, süreç içerisinde istişare ve bilgi alış verişini ilgili diğer kurum ve kuruluşlarla gerçekleştirmekte, bu hususta fikir alış verişinde bulunmaktadır.

Tedbirler belirlenmiş olduğundan, iller tabi ve coğrafi yapıları gereği bu tedbirlerden bir kısmına yönelik yeterli yatırımı gerçekleştirememektedir. Kendi tabi ve coğrafi yapılarına uygun yatırımlar üretmelerine imkan sağlayacak daha lokal tedbirlerin geliştirilmesine ihtiyaç vardır.

Tedbirlere ayrılan fon miktarları farklı ve belirli olup bu fonun bitirilmesi durumunda o tedbire ait yatırımlar yapılmak istense de destek alamayacaktır. Diğer taraftan yatırımın daha az yapıldığı ya da tercih edilmediği böylece ayrılan fonun yeterince kullanılamadığ 1 tedbirler de söz konusu olabilmektedir. $\mathrm{Bu}$ durum fonların daha etkin kullanılabileceği tedbir ve yatırımlarda kullanılamaması problemini beraberinde getirmektedir. Fon akışkanlığının sağlanarak tedbirler arası fon hareketinin sağlanabilmesi durumunda bu problem aşılabilecektir.

Proje hazırlayan danışman firmaların istenen miktar ve nitelikte proje ortaya koyamaması, kırtasiye ve bürokratik işlerin artmasına yol 
açmaktadır bu durum zaman ve maliyet açısından olumsuzlukları beraberinde getirmektedir. Danışmanlara verilecek eğitimlerle bu olumsuzluklar giderilmeye çalışılabilir. 


\section{KAYNAKÇA}

Akın, S. (2008). Avrupa Birliği'nde Kırsal Kalkınmaya Yönelik Mali Yardımlar, Değişimler ve Türkiye'nin Uyum Çalışmaları, Yüksek Lisans Tezi, Ankara Üniversitesi, Sosyal Bilimler Enstitüsü, Ankara.

Bakırc1, M. (2009). “Avrupa Birliği Üyelik Öncesi Destek Fonu'nun (IPA)Kırsal Kalkınma Bileşeni (IPARD),Türkiye'nin Durumu ve Muhtemel Etkileri”, Doğu Coğrafya Dergisi, Sayı: 21.

Başarır, E.P. (2008). Türkiye'nin Avrupa Birliği'ne Uyum Sürecinde Çevre Odaklı Kırsal Kalkınma Politikaları, Uzmanlık Tezi, Tarım ve Köyişleri Bakanlığı, Ankara.

Bilici, İ. (2010). Türkiye'de Kırsal Kalkınmanın Gelişimi ve IPARD Süreci, Yüksek Lisans Tezi, Gazi Osmanpaşa Üniversitesi, Fen Bilimleri Enstitüsü, Tokat.

Bilici, N. (1997). AB Mali Yardımları ve Türkiye, Akçağ Yayınevi, Ekonomik ve Mali Araştırmalar: 1, Ankara

Can, M. ve Esengün, K. (2007). “Avrupa Birliği Kırsal Kalkınma Programlarının Türkiye'nin Kırsal Kalkınması Açısından İncelenmesi: SAPARD ve IPARD Örneği”, Gaziosmanpaşa Üniversitesi Ziraat Fakültesi Dergisi, Sayı: 2.

Çeliktaş, İ. (2006). "AB Katılımı Öncesi Fonların Yapısı", Sayıştay Dergisi, Ekim-Aralık, Sayı:63

Devlet Planlama Teşkilatı (2014). 28.06.2016 Tarih ve 877 Sayılı TBMM Kararı, (2007-2013) 9. Kalkınma Planı,

Günaydın, G. (2000)."Sekizinci Planda Tarım Sektörü", Kamu Yönetimi Dünyası Dergisi, Y11: 1, Sayı: 3-4, ss. 1-6.

Güngör, K. (2000). "Avrupa Birliği'nin Üçüncü Ülkelere Yönelik Mali Yardımları ve Türkiye”, Mevzuat Dergisi, Yı1: 3, Sayı: 35.

IPARD Mevzuatı (2012). Tarım ve Kırsal Kalkınmayı Destekleme Kurumu

IPARD Yatırımc1 Rehberi (2013). TKDK Ankara İl Koordinatörlüğü

Karabacak, H. (2014). "Avrupa Birliği Mali Yardımları ve Türkiye ile Mali İşbirliği”, Maliye Dergisi, Eylül-Aralık, Sayı: 47. 
Karataş, H. (2010). Avrupa Birliği Katılım Öncesi Mali Yardımları, MB Strateji Geliştirme Başkanlığı, Yayın No: 2010/409, Ankara.

IPARD Mevzuat1 (2012). Tarım ve Kırsal Kalkınmay1 Destekleme Kurumu, Sektörel Anlaşma TKDK Başvuru Rehberi (2014). Ankara İl Koordinatörlüğü

Yüksek Planlama Kurumu (2013). 13.06.2013 Tarih ve 3217 Sayılı TBMM Kararı, (2014-2018). 10. Kalkınma Planı

Zülfüoğlu, Ö. (2011). "Avrupa Birliği Bütçesi ve 2007-2013 Mali Perspektifi İzdüşümünde 2011 Bütçesi Üzerinde Bir Değerlendirme”, Çimento İşveren Dergisi, Cilt:25, Sayı:4.

17 Aralık 2001 Tarih ve 2500/ 2001 Sayılı Konsey Tüzüğü, Çerçeve Anlaşma, 04.05.2007 Kabul Tarihli, RGT: 18.05.2007, 26526.

17 Aralık 2001 Tarih ve 2500/ 2001 Sayılı Konsey Tüzüğü, Çerçeve Anlaşma, 99/13759 Sayılı Kararname, RGT: 21.12.1999, 23913.

$\mathrm{AB}$ Bakanlığ1 Türkiye-AB Mali İşbirliği, http://www.ab.gov.tr/files/rehber/08_rehber.pdf (21.08.2014).

Dışişleri Bakanlığı, http://www.mfa.gov.tr/mali-isbirligi (23.07.2014).

Türkiye-AB Mali İşbirliği, http://

www.abgs.gov.tr/index.php?p=5 (17.07.2014).

İktisadi Kalkınma Vakfı (İKV). Mali İşbirliği, Katılım Öncesi Mali Yardım, http://www.ikv.org.tr/maliisbirligi.php (25.08.2014).

http://www.zmo.org.tr/resimler/ekler/e406957d45fcb6c_ek.pdf?ti $\mathrm{pi}=14(23.07 .2014)$.

http://www.tkdk.gov.tr/Duyurular.aspx (01.08.2014)

https://www.tkdk.gov.tr/BasvuruFiles/BasvuruPaketiHazirlamaD okumanlari/IlTedbirListesi/IITedbirListesi.pdf (01.08.2014)

https://www.tkdk.gov.tr/ImzalananSozlesmeler.aspx 01.08.2014) 